\title{
JUSTIFICATION AND JUSTICE: RAWLS, QUINE AND ETHICS AS SCIENCE
}

\author{
DiANA TASCHETTO
}

\begin{abstract}
The relationship between Rawls's theory of justice and Quine's philosophy constitute an almost entirely new topic of discussion. The analysis undertaken in this article aims to show that some fundamental epistemological traits of Rawls's theory of justice may be causally explained by referring to Quine's influence on him. Rawls's assumptions, methods of theory-building and evaluation criteria are addressed and a close nexus between the methods of ethics and natural science is made explicit. In the light of the historical and epistemological analysis presented in this article it may be argued that Rawls's theory of justice as fairness satisfies scientific requirements of evidence and objectivity within the sphere of ethics to the extent it is constructed and justified in accordance to Quine's epistemology.
\end{abstract}

Keywords: Ethics; epistemology; scientific method; holism; pragmatism.

We should strive for a kind of moral geometry with
all the rigor that this name connotes.

J. Rawls, A Theory of Justice (1971)

\section{I}

Any theory, by definition, must meet four basic criteria: conceptual definitions, domain limitations, relationship-building, and predictions (Wacker 1998). Theories are generally built upon extant theory: one does not build a theory from scratch. To be in a position to make constructive moves, therefore, one must be able to criticize a theory, to achieve a proper understanding of the extant theory, being able to explicate it, interpret it and evaluate it. Since criticism precedes construction, one must be able to recognize what counts as a theory if one is to criticize it - not every speculation can be entitled 'theory'. ${ }^{1}$ It is generally accepted that differences of kind modify the methods involved in theory building. She who engages in theorizing must clearly know what sort of enterprise she undertakes to know whether or not she has succeeded in having done it; whilst she must also have set for herself beforehand the goal she is pursuing, since it determines the method she is to follow.

Moral theorizing has been traditionally engaged in and built upon two assumptions, namely (i) the Kantian thesis according to which there is an unbridgeable gulf between statements of fact and statements which express judgments of value/moral judgments and (ii) the understanding according to which any moral theory consists of a set $M$ of moral judgments plus a $n$ number of principles which (a) accounts for

Principia 19(1): 147-169 (2015).

Published by NEL — Epistemology and Logic Research Group, Federal University of Santa Catarina (UFSC), Brazil. 
the judgments set forth or (b) generates them. To grant soundness for a theory $x$ is to bestow epistemological status on $M$ (hence calling its elements 'intuitions') or on the moral principles (hence stating them as 'self-evident' or 'a priori given'). In this context, under the guise of logic we have methods purely arbitrary, everything depending on the choice of the major premise. Consensus regarding conceptual definition, method, interpretation and evaluation could not be achieved. A paradigmatic revolution, however, took place in the field of ethics by the publication of John Rawls's A Theory of Justice: one of the greatest and most influential theoretic architectures in the history of analytic philosophy, its strikingly original approach turned theory acceptance in ethics into a more tractable problem.

The secondary literature on Rawls's moral theory is tremendously vast. The philosophical work that paved the way to A Theory of Justice is, however, frequently overlooked - very little of that literature places Rawls in his historical context. ${ }^{2}$ The primary intention of this article is to show that a closer look at justice as fairness's theoretical structure through historical-cum-epistemological glasses may induce us to reconsider Rawls's intellectual trajectory and the conceptual issues which arise from his theory. Although Rawls is often understood as reviving ethics after its alleged 'death' by the hands of Logical Positivism's famous criterion of meaningfulness, ${ }^{3}$ there is nonetheless little truth in the contours of that story. His concerns are maximally global, scientifically oriented and pragmatically based. I take to be the source of common beside-the-point critiques of Rawls's proposal the under-research of the causal relationships which are (partly, of course) responsible for justice as fairness theory's qualitatively rigorous and internally coherent theoretical traits. Indeed, I suspect that many controversies surrounding A Theory of Justice - e.g. whether Rawls is an intuitionist or a subjectivist about morality, whether he is or should be committed to a theory of moral truth, whether the moral authority of his theory could or should be extended to private matters, whether the ultimate justification of his two principles is contractualist or coherentist, and so on - may appear different once Rawls's theorybuilding moves are analyzed vis-à-vis a scientific methodology and assessed from the standpoint of naturalized epistemology. Commentators often take for granted the aforementioned sine qua non conditions for theory evaluation. This is a mistake: one cannot escape from epistemology in evaluating reasoning. The analysis undertaken in this article aims to reduce these interpretative difficulties, at least to a degree.

The tradition that is typically thought to have foreclosed the possibility of rational political thought, Vienna Circle's Logical Positivism, is actually the source of Rawls's original conception of ethical theorizing. John Rawls's philosophical reflection started as an attempt to construct an ethical theory in accordance to the positivistic prescriptions and requirements put forward by C. J. Ducasse in his (1940b) ${ }^{4}$ and, also influenced by the non-foundational work of logical positivists such as Otto Neurath (Foundations of the Social Sciences), Rudolf Carnap (Philosophy and Logical

Principia 19(1): 147-169 (2015). 
Syntax; Introduction to Semantics) and Hans Reichenbach (Experience and Prediction), the young Rawls ${ }^{5}$ understood that moral theories cannot be true absolutely or inherently. Moral Platonism and intuitionism were by him completely discarded. Rather, the task of the moral philosopher, he suggested (1946), is to construct and predict noncontroversially competent moral judgments and to identify formal principles that explain appearances: whenever moral philosophers attempt to refute an ethical theory they appeal to a specific set of facts, namely, the facts of ordinary ethical judgment. Ethics, Rawls acknowledges, is an empirical inquiry. Ethical theories must then be predictive, testable, falsifiable. We could repeat for rules of ethics all it is said of scientific rules. Rawls, in his "A Brief Inquiry into the Nature and Function of Moral Theory" refers to this work as ethics as science.

Since his unpublished essays have been deposited and made available at the Harvard University Archives, Rawls's early positivist, scientific-oriented aspirations in the field of ethics have been subject of fruitful analysis. Elsewhere well-presented and discussed, ${ }^{6}$ these early commitments need not detain us. Here I take that relation as settled and assume its epistemological/methodological results. Of crucial importance, however, is what this first commitment entailed: ethics as science remained, I hypothesize, an ideal Rawls would like to achieve. The metaethical turn from "A Brief Inquiry into the Nature and Function of Ethical Theory" (1946) to A Theory of Justice (1971) is a consequence of a shift of understanding of epistemology's and philosophy of science's practical rules and theoretical standards triggered by the work of Rawls's Harvard colleague Willard V. O. Quine: prevailing orthodoxies within analytic philosophy were radically challenged and, by means of Quine's work, slowly but surely overthrown. Science started to be understood as a matter of context-dependent plausibility and not of a context-independent 'organon of thought'. ${ }^{7}$ By extension, so did ethics. Rawls's method, I shall argue, is a version of Quinean holism applied to moral theory. ${ }^{8}$

The breakdown of this article is as follows. The next section provides an overview of those aspects of Quine's philosophy which are pertinent to the issues of theorybuilding and justification in the context of Rawls's theory of justice I am here concerned with. This presentation is required for the sake of clarity, that is, so the parallel between Quine's ideas and their application in justice as fairness's theory to be sketched in section III be brief and explicit. Hopefully, this attempt to explicate the objective features of Rawls's proposal through Quinean lenses will prove to be epistemologically adequate, forcing us to give Rawls's theory of justice its due objective status. ${ }^{9}$

\section{II}

Quine is a towering figure in analytic philosophy. His writings, as is the second literature on him, are massive. The desideratum of covering even the main topics of 
his philosophy thoroughly as clarity and rigor require in so brief a sketch as this is hopeless. In spite of the broad range of subfields of philosophy to which Quine has made profound contributions (philosophy of science, philosophy of mind, philosophy of mathematics, philosophy of language, metaphysics, epistemology, logic and set theory), his work has a systematic unity. Here I shall try to indicate and briefly describe certain features of his thought that can be isolated for purposes of analysis which I think have influenced Rawls's conceptions of theory-building, ontology, and justification. Assuming that some readers are not well acquainted with Quine's cornerstone philosophical commitments, to compensate the roughness of the outlines here drawn complementary readings will be indicated. Readers well-schooled in Quine's philosophy may skip this section altogether, if so they see fit.

\section{Holism}

The grounds upon which empiricism was (supposedly) made rational, sound, and, therefore, trustworthy (its 'dogmas', in Quine's terminology) are twofold: first, the assumption that there exists a logically unbridgeable distinction between linguistic and factual truths, that is, of analytic sentences (true by definition; knowable by knowing the meanings of the constituent words alone) and synthetic ones (sentences whose truth is knowable by both knowing the meaning of the words and their correspondence to facts; correspondence which can be readily be made by simple and eye-catching procedures and/or 'ostensive rules'). Second, a direct consequence of logical empiricists' verifiability principle ('the meaning of a statement is its method of verification') is the reductionist thesis according to which every meaningful statement can be reduced to a construct of immediate experience. Seeking to legitimize philosophical talking on a basis shared with the empirical sciences, logical empiricism embraced the view that only sentences which were verifiable either (a) logically or (b) empirically could be labeled cognitively meaningful.

Once, however, a close analysis is undertaken, many difficulties arise: when we try to draw a boundary line between synthetic/analytic statements we are forced to beg the question, and there seems to be no breaking out of that circle. In order to explain the notion of analyticity philosophers need to appeal to other notions such as synonymy - notions that are either hopelessly unclear or which by their turn depend on the notion of analyticity (Quine 1951). Quine argues that empiricism, in assuming analyticity uncritically is thereby indulging in metaphysics: these ideals of knowledge' are of a kind that it is possible neither to (a) identify the logical distinction upon which they are grounded nor (b) to build on them. The dichotomy between observational and theoretical terms is a pragmatic (psychological) distinction which has nothing to do with the logical status of the two kinds of term: "My present suggestion is that it is nonsense, and the root of much nonsense, to speak of a linguistic compo-

Principia 19(1): 147-169 (2015). 
nent and a factual component in the truth of any individual statement." (Quine 1951, p.39). Observation is theory-laden, that is, the interpretation of an observation language is determined by the theories which we use to explain what we observe, and it changes as soon as those theories change. But if the interpretation of a statement (say, for instance, 'I am in pain now') depends upon the theories used (in the example stated thus upon psycho-physiological theories) then we cannot interpret the logical complexity of the statement independently of those theories. Hence, as Quine puts it, "the typical statement about bodies has no fund of experiential implications it can call its own." (Quine 1969, p.79). The unity of significance is neither a word (as for classical empiricists such as Locke and Hume) nor a proposition (as argued Frege and, following him, Russell and Wittgenstein) but the whole system of beliefs. Quine's countersuggestion, as he calls it, is that "our statements about the external world face the tribunal of sense experience not individually but only as a corporate body." (Quine 1951, p.38). This is holism: the view that many of our supposedly empirical sentences have implications for experience only when they are taken together with a larger or smaller body of other sentences. It is the more inclusive theory that has such implications, not the individual sentence by itself. ${ }^{10}$

\section{Naturalism}

Quine's naturalism consists of two complementary and intertwined theses, one negative, one positive. The negative thesis asserts that there is no first philosophy: there is neither an a priori nor an empyreal foundation outside science upon which science can be grounded (i.e., justified or rationally reconstructed). The positive thesis states that science is the measure of both what there is (ontology) and how we know what there is (epistemology). The domains of the philosopher and of the scientist are understood to be distinct but overlapping. Relying on scientific findings, Quine maintains that physicalism ${ }^{11}$ is the best metaphysical theory we have, whilst empiricism ${ }^{12}$ is the best theory we possess of how we know what there is. In Word and Object (1960, p.275) Quine puts the point as follows:

Given physical objects in general, the natural scientist is the man to decide about wombats and unicorns. Given classes, or whatever other broad realm of objects the mathematician needs, it is for the mathematician to say whether in particular there are even prime numbers or any cubic numbers that are sums of pairs of cubic numbers. On the other hand it is scrutiny of this uncritical acceptance of the realm of physical objects, or of classes, etc., that devolves upon ontology. Here is the task of making explicit what had been tacit, and precise what had been vague, of exposing and resolving paradoxes, smoothing kinks, lopping off vestigial growths, clearing ontological slums ... The philosopher's task differs from others', then, in detail; but in no such drastic way as those suppose who imagine for the philosopher a

Principia 19(1): 147-169 (2015). 
vantage point outside the conceptual scheme that he takes in charge. There is no such cosmic exile. He cannot study and revise the fundamental conceptual scheme of science and common sense without having some conceptual scheme, the same or another no less in need of philosophical scrutiny, in which to work.

Repudiating first philosophy (i.e., foundationalist epistemology, both rationalist and empiricist) the naturalized philosopher acknowledges the advantage and the legitimacy of making use of psychology and allied sciences (e.g., neurology, genetics, linguistics, and so forth) in attempts to formulate answers for fundamental questions of philosophy (e.g. a philosopher $x$ who wants to link theory and phenomena upon whatever epistemological basis she likes is free to rely on talk of particles, molecules, black holes, nerve endings, and so on, for these things belong to the ontology of the natural science of $x$ 's time). Philosophy must make free use of whatever scientific findings may suit its purpose: Quine embraces Neurath's likening "science to a boat which, if we are to rebuild it, we must rebuild plank by plank, while staying afloat in it. The philosopher and the scientist are in the same boat" (Quine 1960, p.3). Contrary to the hopes of traditional epistemologies, there will be no deducing ontology from epistemology: all evidence, says Quine (1960), is sensory evidence. Naturalized philosophers are prohibited from making appeals to any alleged a priori (or otherwise transcendental) sources of knowledge, for they deny the same to the objects of their inquiry. ${ }^{13}$ This philosophical-cum-scientific theorizing, as we shall see in section III, is rich in practical consequences.

\section{Pragmatism}

If one intends to be true to accepted standards of objectivity and rationality, i.e., proof, consistency, factual evidence, and so forth, one is led to the conclusion that "[...] The world view [i.e., natural science] which lent plausibility to this modest account of our knowledge is, according to this very account of our knowledge [i.e., empiricism], a groundless fabrication.” (Quine 1976, p.229). A naturalized philosopher neither attempts to rationally reconstruct the ontology of natural science from some sort of pristine, unadulterated sense data nor does she try to deduce the ontology of science from sensory input, for the very notion of unadulterated sensory experience is dubious and there are no unique evidential relationships to be found between experience and the theory it is intended to support. In Quine's words,

It is thus our very understanding of the physical world, fragmentary though that understanding be, that enables us to see how limited the evidence is on which that understanding is predicated. It is our understanding, such as it is, of what lies beyond our surfaces, that shows our evidence for that understanding to be limited to our surfaces. (1976, p.2)

Principia 19(1): 147-169 (2015). 
We know that experience, taken by itself, is mute. Reference is a relative matter, like position, and time. We have also learnt that (i) observation is theory-laden and that (ii) theory is underdetermined by experience in several ways. ${ }^{14}$ How can we explain science's undeniable success?

Holism opens the way for fallibilism: even though Quine insists that our ontology (physicalism) tells us that our epistemology is reliable and our epistemology tells us that ontology is warranted, both of these claims are part of science itself and are, consequently, mutable and fallible. Truth and falsehood depend on a series of factors, and the more complex the relationship between the elements of a theory, the more exposed to criticism and fallible the theory is. Quine argues that pragmatic considerations govern science and explain its effectiveness. Science, says Quine, must be understood as a tool - more specifically, a tool for making predictions - and must be evaluated as any other tool is, viz., by its performance in practical functions: How useful is it? How well does it work? Does it do the job it was designed for? And so on. Both (a) internal coherence changes and (b) changes required by pressure of phenomena are evaluated by whether and how they improve the tool. The tool is shaped by the job it was built for and for those who will be handling it: science is adjustable in response to its perceived usefulness. Performance problems must be diagnosed as changing requirements of kinds (a) or (b). Difficulties of diagnoses due to epistemological bias of the sort (i) and (ii) must be dealt with by appealing to what have come to be called 'extra-empirical' or 'pragmatic' virtues (Quine 1960), the most important of which are simplicity (Occam's razor), familiarity of principle (Neurath's boat), sufficient reason (shunning of gratuitous singularities) and fruitfulness. ${ }^{15}$ This point of view places Quine - once saluted as 'the last pragmatist ${ }^{16}$ — in the tradition of William James and American pragmatism. ${ }^{17}$ In the Neurathean spirit of accounting science from within science, there is no vantage point from which we can survey all competing, equally warranted ontologies. The full weight of Quine's pragmatism lies on his naturalism, for it turns an obvious weakness (circularity of justification) into overpowering strength (effectiveness). ${ }^{18}$ This point will be further discussed in the next section, where we shall see this epistemological account applied in Rawls's theory of justice.

\title{
III
}

\author{
The theorems of a physical theory are \\ propositions. In order to judge of their coincidence \\ with empirical laws, those laws must first be \\ translated into propositions. The entire art of the \\ student of ethics consists of expressing by
}

Principia 19(1): 147-169 (2015). 
means of words moral rules of which we all have a vague intuition. It is because this work is done only rarely and not very rigorously that theories of ethics are so uncertain.

J. Rueff, From the Physical to the Social Sciences

I must disclaim any originality for the views I put forward.

J. Rawls, A Theory of Justice (1971)

Any theoretical argumentative chain starts by determining (and, ideally, making explicit) the assumptions upon which the whole theoretical structure will be built. Secured as it is against an answer, the question of what sort of concepts and/or arguments counts as proper assumptions need not detain us. However, what is taken for granted, although logically vacuous, is by no means psychologically (or epistemologically) vacuous: one generally begins with what is intuitively plausible, wellestablished and generally accepted. It is widely known that in his Geometry Euclid's method consists in assuming a small set of intuitively appealing axioms and deducing many other propositions (theorems) from these. From the things Rawls assumes in his theory of justice, the following concern us here: (i) people are, ceteris paribus, rational; (ii) people are capable of a sense of justice; (iii) even people with different beliefs can agree on some principles to resolve basic conflicts over the distributional effects of social institutions; (iv) consensus in some sense is necessary for the legitimate exercise of state power; (v) the traditional distinction between innate rationality and products of acculturation is unsound; (vi) ethics is an empirical enquiry; (vii) people have the rational wish for a theoretical integration or equilibrium of all their ethical judgments with their most confident, primitive ones.

Natural science owes its objectivity to its intersubjective checkpoints in observation sentences. Objectivity, as we know, is a value. To label a thing 'objective' means to ascribe some importance to it and to say that we approve of it. Ethics - as science - is therefore either democratic, i.e., intersubjective, or it is self-contradictory: if an ethical theory is to be edified and tested, then we ought to apply to ethical inquiry just the rules we have learnt to apply to inquiry in general. ${ }^{19}$ Rules, as we know, live on their popularity - and W.V.O. Quine was the main agenda-setter in post-World War II epistemology and related fields. Objectivity is required by a theory of justice by assumptions (iv) and (vi). Assumptions (v)-(vii) led Rawls to embrace a Quinean approach to ethical justification. A composite containing a normative principle and a descriptive statement could be regarded in a holistic fashion and be empirically tested. This understanding, as we will see, entailed an entirely new attitude toward ethics and ethical theorizing. In this section, I shall proceed as follows: Rawls's methodological moves will be described and the general Quinean background of his 
theory of justice made explicit. In order to do so I must appeal, when clarity requires, to the ideas presented in section II. I shall also discuss some consequences of this philosophical-cum-scientific procedures and show why I think such an account is to be preferred over its alternatives. ${ }^{20}$

To elaborate: the guiding idea from which Rawls begins his reasoning states that

[...] principles of justice for the basic structure of society are the object of the initial agreement. They are [...] to regulate all further agreements; they specify all kinds of social cooperation that can be entered into the forms of government that can be established. This way of regarding the principles of justice I shall call justice as fairness. (Rawls 1971, p.11, my italics)

In order to construct such principles, Rawls's theory-building moves can be understood by means of an analogy between ethical and scientific theorizing. Let us see. To answer physical science's most important question, namely, "what are the basic laws of nature?" it is generally acknowledged that one has to deal first with a prior question, viz. what is the nature of the scientific method. Assumed ethics is an empirical theory, by extension, to answer the most important question of ethics, viz. "what are the basic principles of morality?" one has to deal first with its correspondent prior question, namely, what is (are) the method(s) or procedure(s) for determining the answer to the first question. Ethics might be, Rawls insists, more analogous to the study of inductive logic than to any other inquiry (Rawls 1971). In justice as fairness theory answers are offered to both questions, i.e., proposals are made both about the basic principles of morality (the liberty principle and the difference principle) and about the proper method(s) or procedure(s) for determining these principles (reflective equilibrium, the original position procedure and the concept of public reason).

The same requirements of evidence and objectivity apply to both ethical and natural science. We attempt to extract our moral principles from our common-sense judgments as laws of nature are abstracted by induction; as laws of nature are tested by observation statements, moral principles are verified by testing them against our common-sense judgments. ${ }^{21}$ Devised to nullify the effects of specific contingencies which put men at odds for the choice of principles, the original position procedure sets constraints of a sort that the same principles are always chosen. Similarly, an experimental scientist relying on a ceteris paribus clause is expected to devise reproducible experiments. In this regard, if a shared point of view can be made welldefined, a determined set of principles should be the outcome of Rawls's method's application (given that (a) all men share the same psychological traits and rational capacity and (b) all are equally informed and situated (veil of ignorance ${ }^{22}$ )) just as a given sum is the outcome of a problem of addition. ${ }^{23}$

I would like to inject one note of caution, however, before proceeding. To push the aforementioned analogy may be misleading, and in the following sense: we must not 
expect from the theory as a whole more precision than its subject-matter admits. ${ }^{24}$ This is of great importance. Although standards and methods are alike, moral geometry cannot be made as rigorous as, say, Riemannian geometry. The former cannot set up as solid grounds for ethics as the latter does for general relativity theory. Causal relations are not as straightforward in social and psychological phenomena as they are in physical phenomena. Moral judgments differ from cognitive ones in their relation to observation. Laws of nature are atemporal; moral customs change through time. As an empirical theory, ethics must recognize that contingencies might demand adaptations in the system: life brings into play innumerable forces confronting our judgments. Rawls's moral system does not direct our judgments nor resolve disagreements once and for all — it tends to direct our judgments in coherence to our deepest convictions and to reduce disagreements. It tells us what to do in order to be fair. It is only in this sense that ethics is as universal and necessary as are the physical sciences.

Let us leave the analogy aside, for now. It is well-known that Quine was quite a conservative in ethics and that he evicted moral questions from his philosophy. ${ }^{25}$ Rawls does not offer a philosophical commentary on Quine's moral views and direct references to Quine's philosophy in Rawls's corpus are rare. ${ }^{26}$ What he does is simply to include Quine's notions of explication, confirmation and scientific inquiry in his methodological agenda to face ethical questions. Rawls - as Quine - is a system builder. Unless one looks at his theory as a whole, holistically, one will not see the motivation or justification behind its constituent parts. The philosophical relevance of the analysis undertaken in this article lies on the extent it contributes to such understanding. Now then that we are somewhat acquainted with theory-building requirements (section I), with the problem and the phenomena selected by Rawls for correlation and explanation, with the type of reasoning he intends to follow and with his assumptions, the aforementioned epistemological relationship between Quine's method and Rawls's theory of justice can be made explicit. For that purpose, let me briefly present the process of reflection and construction of principles articulated by Rawls. The procedure shall go as follows:

We start with a set $J_{0}$ of considered judgments. / We examine our moral intuitions, discarding those which are (a) unstable, (b) vague, and/or (c) in which we lack confidence. We retain only those which we are willing to affirm confidently after careful thought. / We provisionally adopt a decidable set $P_{0}$ of principles from which we imagine the considered judgments can be derived. / We strive to articulate the elements of $P_{0}$ in a logically weak and widely shared way, or to derive them from logically weak and widely shared constraints on an original position. / We proceed to reflect on our judgments and principles against a set, say, $T_{0}$ of background of relevant theories - theories of society, of persons, of the proper conception of the good, of moral education, of the task of ethics in society, of which religion is the 'true' one, and so forth. Moreover, as Rawls treats reflective equilibrium in the primary stance 
as justifying principles of justice only indirectly, by way of justifying conditions stated on the original position, in addition to $J_{0}, P_{0}$ and $T_{0}$ we shall take into account constraints $C_{0}$ placed on an ideal circumstance of choice (i.e., the restrictions sketched by the veil of ignorance). ${ }^{27}$

Acquainted with the required procedural steps, our reflection proceeds in stages. At any stage $n+1$ we look for discrepancies among (a) our sets $J_{n}$ of considered judgments and (b) our $P_{n}$ counterpart set of principles; taking at each stage $n$ our set $T_{n}$ of background theories and our set $C_{n}$ of constraints placed at the original position situation. This process goes on until we reach a set $\phi$ of $\left(J_{n}+P_{n}\right)$ that is internally consistent [narrow reflective equilibrium] plus a set $\psi$ of $\left(J_{n}+P_{n} \equiv T_{n}\right)$ [wide reflective equilibrium]. The latter determines which principles of justice we ought to adopt [a moral theory is justified]; the former gets us to arrive at principles that 'best account for' the cases under assessment [moral judgments are justified].

Keeping to the essentials, most of justice as fairness's Quinean-rooted epistemological traits which concern us here can be inferred from this procedure alone. In order to do so, we can gain in clarity beginning by making somewhat explicit the distinction between (1) foundational and (2) coherentist ethical theorizing. Let's see. (1) postulates that a moral belief $p$ is justified if and only if $p$ is (a) fundamented (selfjustified) and (b) based on an inference chain of cornerstone beliefs. (2), on the other hand, asserts that $p$ is justified while satisfying the constraints set by a given system $x$. The intratheoretical coherence of $p^{\prime} s$ in $x$ [partially] explains one's support of $x$. In (1) $p$ is either (i) given a priori or (ii) intuitively grasped. In (2), on the other hand - whose detailed procedural steps were above outlined - the grounds are bricked rather differently. Let's take $p^{\prime} s$ for a set of conceptions of a given moral system. Principles such as 'equality', 'good', 'person', 'community' and so forth, which play a main role in any moral theory, cannot be understood/discussed/analyzed as 'entities' or something of the like but just and only as elements of a system. Their meanings are directly conditioned by the system's dependent variables - i.e., their meanings are constructed in accordance to the constraints posited by the elements of the sets $\phi, \psi$ and $C_{n}$.

As described in section II.1, Quine has shown the unattainability and the logical vacuity of foundational approaches: there is no such thing as 'absolute meaning'. The assumption that man is capable of reactions (abstract ideas and sensations) of a sublime kind which by their very nature allow us to confer meaning upon expressions which are their verbal manifestation lies on a metaphysical fallacy. ${ }^{28}$ Given some phenomenon, one can always construct (or 'discover', or 'intuit') an infinite series of descriptions, all of them fitting this particular phenomenon. ${ }^{29}$ Claims of truth can be raised only with regard to particular theories: it might be asserted that (a) the chosen theory has been shown to be true or (b) it is possible to assume its truth, even though (ba) the theory has not been established (e.g. effective theories such as quantum 
field theory) and/or (bb) it is in conflict with established views and facts (e.g., nonrelativistic quantum mechanics). To label a theory 'true' means simply to concede that the theory is the best existing way of accounting for the facts we currently know and/or is the most successful tool for predicting future outcome. Nonetheless, in both ways the burden of proof weights heavy: everything to which we concede existence is a posit from the standpoint of a description of a process of theory-building. Ontology is as tentative and mutable as science itself. So is ethics. If we are to have learnt from history, we shall not strap our ontological ties too tight: the acknowledgment of such constraint led Rawls to embrace, at once, fallibilism and pragmatism. ${ }^{30}$ Questions of meaning cannot be decided by introspection or by attendance to what is immediately given. Says Rawls:

There is a definite if limited class of facts against which conjectured principles can be checked, namely, our considered judgments in reflective equilibrium. A theory of justice is subject to the same rules of method as other theories. Definitions and analyses of meaning do not have a special place: definition is but one device used in setting up the general structure of theory. Once the whole framework is worked out, definitions have no distinct status and stand or fall with the theory itself. In any case, it is obviously impossible to develop a substantive theory of justice founded solely on truths of logic and definition. The analysis of moral concepts and the a priori, however traditionally understood, is too slender a basis. Moral philosophy must be free to use contingente assumptions and general facts as it pleases. (Rawls 1971, p.51, my italics).

And he goes on:

More likely candidates for necessary moral truths are the conditions imposed on the adoption of principles, but actually it seems best to regard these conditions simply as reasonable stipulations to be assessed eventually by the whole theory to which they belong. There is no set of conditions or first principles than can be plausibly claimed to be necessary or definitive of morality [...] Therefore, we do better, I think, to regard moral theory just as any other theory, making due allowances for its Socratic aspects. There is no reason to suppose that its first principles or assumptions need to be self-evident [...] Justification rests upon the entire conception and how it fits in with and organizes our considered judgments in reflective equilibrium. As we have said before, justification is a matter of the mutual support of many considerations, of everything fitting together into one coherent view. (Rawls 1971, p.578-9, my italics).

Once the presumption of truth is removed, it is possible for Rawls to overcome the blind alley produced by the dichotomy 'Reason vs. History' and pave a way to use reason in history. The moral theorist's problem is a practical problem - a political 
problem - of rational deliberation and public courses of action. Coercion and persuasion are inconsistent with our understanding of democracy. Both (a) the fact or reasonable pluralism and (b) the empirical character of ethical theory demand the rejection of authoritarianism (or, absolutism) and skepticism (or, positivistic relativism) in ethics. Once again, the method which has proved to be so fruitful in the physical sciences can be applied to the social sciences as well: 'truth' is to be regarded as a provisional state of unanimous certainty after considered reflection and public confrontation of views. Pragmatism is the epistemological justification of democracy: ${ }^{31}$ what is true for the competent judges matters (pace the skeptic) and may be revised over time (pace the absolutist). In "The Origin of Ethical Reflection", Rawls writes:

We think of knowledge as something publicly testable; and we think of it as subject to future correction and amendment. We reject, therefore, that knowledge which is based in the merely private and personal, and which claims complete certainty and infallibility. Any belief which is put forward as an insight of a single individual, and put forward as being certain, immediately strikes us as a vain pretension. The characteristics of scientific inquiry are many and complex, and to know correctly what science is, we should have to study a model science with some care. Yet two features of it we do know, and they are: (i) that it is a communal and social investigation, whose results are confirmable in principle by anyone having the necessary intelligence and ability to understand them; and (ii) we think of such knowledge, not as having been laid down once and for all, but as being subject to progressive modification and correction. (Rawls in Botti (2014), p.354).

In "Remarks on Ethics", Rawls makes explicit the analogy of ethics with natural science:

However much people like Dewey and Northrop try to set up [what they think is] a logical procedure for the finding of scientific statements, they are attempting what cannot be done. The logic of induction enters as a selection operator upon the statements proposed as valid. It does not concern their past history, i.e., how they came to be asserted by some mind. Equally so, then, with ethical principles. How we come to know them may be, and in fact is, an important empirical study, and one which throws considerable light upon our moral ideas. This last question can only be decided in terms of the decision tests which we ought to apply to ethical statements, and how well the statements meet these tests. What tests we ought to apply is, of course, a basic problem of ethical theory. (Rawls in Botti (2014), p.366).

The tests to which ethical principles ought to be submitted will later be formulated by Rawls by an appeal to another of Quine's central methodological concepts: that of explication. Quine's concept of explication is primarily shaped by his notion of ontological parsimony: it means, in short, finding an exact substitute for an inexact 
explicandum. Quine emphasized puzzle-solving motivations to replace troublesome concepts by clearer, simpler ones that preserve theoretical useful features. Explication, says Quine, is elimination: "In all these cases, problems have been dissolved in the important sense of being shown to be purely verbal, and purely verbal in the important sense of arising from usages that can be avoided in favor of ones that engender no such problems" (Quine 1960, p. 261). The slogan can however suggest what it does not entail - viz. that all explications are overthrows. Explication is elimination with (adequate) replacement; and it is the conservativeness of some replacements the point to be made. Quine's account of philosophical analysis reflects clearly his naturalistic and pragmatic commitments:

\begin{abstract}
A similar view can be taken of every case of explication: explication is elimination. We have, to begin with, an expression or form of expression that is somehow troublesome. It behaves partly like a term but not enough so, or it is vague in ways that bother us, or it puts kinks in a theory or encourages one or another confusion. But also it serves certain purposes that are not to be abandoned. Then we find a way of accomplishing those some purposes through other channels, using other and less troublesome forms of expression. The old perplexities are resolved. (Quine 1960, p.260). ${ }^{32}$
\end{abstract}

Frequently overlooked, the justificatory and heuristic force of Quine's conception of explication in justice as fairness's theoretical structure is of great importance: it is the appeal to philosophical analysis as elimination which enables Rawls to solve the priority problem. Recall the processes of wide and narrow equilibrium previously sketched: the mutual adjustment of general principles and particular considered judgments confirms a moral theory just as the mutual adjustment of theory and evidence confirms a scientific theory. ${ }^{33}$ Let $J$ and $P$ represent our judgments and principles in reflective equilibrium, and let $C n(P)$ represent the set of logical consequences of the principles chosen under due reflection. Principles and judgments must therefore harmonize in the sense that $C n(P)=J$. This mutual adjustment of general principles and particular considered judgments is hardly simple, however: we may face epistemological problems such as nonmonotonicity of the process; pathdependent results and no algorithm to follow at each stage of reflection; expansion of the sets of general principles and considered judgments; and so on. ${ }^{34}$ Furthermore, Quine taught us (1975) that (a) theory is underdetermined by all possible evidence [in principle, local algorithmic strategies can produce different sets of principles of justice equally well-supported by our considered judgments] and (b) observation is theory-laden [the principles chosen may have a coercive effect over its subject matter, the moral judgment]. The moral skeptic can then reasonably ask: by what standards are Rawls's principles better than others? The answer lies precisely on an appeal to Quine's account of explication. According to Rawls, his liberty principle and his difference principle are superior and consistent replacements for the somewhat trouble-

Principia 19(1): 147-169 (2015). 
some concepts people intuitively use. The case in point is, then, that these principles play such a role without losing the semantic and conceptual importance of the original ones. They enable us to describe more rigorous expressions that are in principle available for making theoretical sense of competent judges' deepest convictions. This is an account which is strongly influenced by naturalism: theory organizes phenomena in order to tell a coherent story. A complex science such as ethics deals simultaneously with a sizable number of factors which are interrelated: here lies the importance of psychology, choice theory, sociology, economics - science, in short - within the sphere of ethics. Rawls himself describes the result of his analysis as elimination:

I maintain that we all could agree to eliminate ethical terms in this way, that is, so to replace them (or to abandon them). I'm inclined to think that this could be a good thing, and look forward to the time when all (unanalyzed) ethical talk ceases and the emotive or the rhetorical use of moral concepts disappears. (Rawls in Bevir \& Galisanka (2012), p. 26, italics in the original).

On his seminar notes, Rawls addresses to Quine directly:

What I would claim as a sufficient minimum (at least) is that there is a naturalistic theory which can be substituted for the ordinary conception and which allows for what we want on reflection with nothing important being left out (Quine's view of explication as elimination, example of ordered pair as defined in logic as substitute for notion of relation). (Rawls in Bevir \& Galisanka (2012), p. 27, italics in the original).

The reported passages support the hypothesis I have tried to advocate that Rawls's attempt to situate ethical theorizing within the confines of empirical sciences is holistically justified and pragmatically oriented. I have tried to show that some fundamental epistemological traits of Rawls's theory of justice may be causally explained by referring to Quine's influence on him. Many innocuous philosophical interpretative quarrels may be avoided when the normative and empirical credentials of Rawls's theory are examined from a Quinean standpoint: Rawls subscribes to a political notion of pragmatism and to an intersubjective understanding of ethical theorizing. Constitutional essentials and matters of basic justice must be settled by appealing to political values, and to those values alone. This is a direct consequence of (a) the fact of reasonable pluralism; (b) the communal character or ethical inquiry and (c) the political urgency for a heuristic theoretical device to settle public disagreement. Moral geometry is created. Ethical rules are theory-dependent. Truth is not the primary currency of practical reason; sound political principles are reasonable means to a reasonable end: realizing as maintaining as free equals mutually intelligible and justifiable political relations. The only test justice as fairness must face is how well it fits its purpose. ${ }^{35}$ 
Final Comments. Let us see now where we stand. I started by pointing out some features of criteria for theory building in general and I indicated the scientific rigor with which Rawls, by influence of Ducasse and the proponents of Logical Positivism, established the standards and epistemological parameters of proper ethical theorizing. In section II, I sketched very briefly some aspects of the very systematic philosophical thought of Willard V. O. Quine. The main point to be made is that there is no theory of knowledge distinct from science and no external standpoint from which we can question that science. Philosophy itself is subjected to the standards of clarity, evidence and justification which are most explicitly displayed and successfully implemented in science. The concern to separate the world of truths into necessary and contingent ones cannot hold: one must treat metaphysical matters pragmatically. Self-respecting empiricism entails a reduction per absurdum proof of traditional epistemology. In section III, I considered Rawls's assumptions, methods of theory construction and evaluation. His understanding of what is at stake and what counts as a solution is quite novel in ethical theorizing; by appealing to Quine's philosophy I have tried to show the naturalistic and holistic traits of Rawls's rationale and, by making analogies with methods and processes undertaken in science, the systematic reasoning he follows. ${ }^{36}$

Just as one looks at water differently after well-acquainted with chemistry, at a grain of sand differently if one is schooled in molecular quantum mechanics and at the heavens differently after mastering cosmology theories, Rawls's theory of justice can only be fairly appreciated and evaluated when one keeps in mind the naturalist and pragmatist ${ }^{37}$ concerns which pervade his philosophical thought. Rawls is a widely-celebrated political thinker - his philosophy, nonetheless, is far more powerful than generally recognized. Many commentators have not sufficiently appreciated the extent to which his ideas fit together to form a coherent whole. Understood as a far-reaching philosophical project and as an empirical theory of morality, justice as fairness is both descriptive and normative. It is descriptive to the extent it is a theory of our moral sentiments; it is normative to the extent that it demands consistency between our deepest moral convictions and our common-sense, everyday judgments. ${ }^{38}$

Critiques towards Rawls's system such as "There can be no justice without truth" (Raz 1990, p.15) and "[...] this Rawlsian view fails unless it adds that its foundational doctrine, the acceptance criterion, is at least approximately true" (Estlund 1998, p.275) mistake loaded philosophical jargons for epistemological standards. Their claimers fail to understand that one must determine the semantical usage of the ethical statements by a suitable theory and only then decide whether or not the semantical usage of 'true' applies to those sentences. A theory of justice does not attempt to solve controversies such as "What do the words 'justice', 'injustice', 'right', 'wrong', 'fairness', and so on, considered as it were in vacuo, mean?". By verbal convention, such words can be made to mean anything one chooses. ${ }^{39}$ Rather a proper theory of justice shall solve problems such as what these words imply in the context 
of ethical theory $x$ in cases of kind $y$ by persons with such and such characteristics. The ontological and epistemological worth of the elements of any theory can be evaluated only holistically. Rawls's ontological abstinence follows directly from the fact of reasonable pluralism: this is how the relationship between unity and variety is settled in his theory. Why, I ask, would Rawls commit his theory of justice to higher-order truths, whatever these may be, when they are not necessary for the effectiveness of the theory altogether? Why open the door for gratuitous ontological controversies, sacrificing a whole treasure of well-established results? A theory held true may turn out false; knowledge is frequently disfigured by error. After Newton, we should know better. The existence of different world views - the fact of reasonable pluralism is the backbone of Rawls's theory. Not the problem. Justice as fairness cannot reasonably claim in favor of a social harmony couched in the terms of a monolithic truth which would be non-political by definition. ${ }^{40}$

The beauty of Rawls's theory of justice coherence is due to a great extent to its objective, scientifically based, mutually-supporting traits. I assume, following Quine, that being (transcendental) truth beyond our reach, success is the goal we must aspire. Philosopher of science Paul Feyerabend has claimed (1975) that one can offer no objective reason to regard science superior to myth, theology, or necromancy, for that matter. As for me (and I guess I am not alone at this) I ironically say I would like very much to see a necromancer send a ship into space. Our knowledge is sciencebased because science has succeeded. Tremendously. Assuming all knowledge is in the same general line of business, philosophy, as a part of our knowledge which aims to be successful, shall aspire to scientific standards. ${ }^{41}$ I understand Rawls as embracing this down-to-earth method of philosophizing. My reading of him is epistemologically naturalized and scientifically based; my plea for his theory is pragmatic: it is to be preferred over its alternatives simply because it works best. ${ }^{42}$

Note regarding objections. It happens frequently that many objections to ethical theories are irrelevant or beside the point. To properly evaluate a theory one has to keep in mind the epistemological considerations put forward in section II and the theory-building criteria briefly sketched in the beginning of section I. This discussion will meet its purpose if it somehow mitigates this situation in the context of justice as fairness's theory. Nonetheless, a few more words might be valuable. Would-be criticizers must keep in mind that the only relevant objections to Rawls's theory of justice concern (a) claims of internal inconsistency; i.e., conceptual incompatibilities between either processes or terms; (b) lack of correspondence with our moral convictions; i.e., the logical consequences deduced from the principles chosen under due reflection are shown not to match our considered judgments; (c) the untenability of the process of reflection; i.e., whether one can prove that at no stage $n+1$ of our reflection $C n(P)_{n}=J_{n}$ and (d) the ineffectiveness of the reflection scheme as a whole 
in reducing disagreement. As any empirical theory, justice as fairness may be falsified by either (i) logical or (ii) empirical reasons. No other objections are relevant since justice as fairness concerns nothing else whatsoever.

\section{References}

Ayer, A. J. 1936. Language, Truth, and Logic. London: Gollancz.

Bevir, M.; Galisanka, A. 2012. John Rawls in Historical Context. Draft. p.1-45.

Bonevac, D. 2004. Reflection Without Equilibrium. The Journal of Philosophy 101(7): 363-88.

Botti, D. 2014. John Rawls, Pierce's Notion of Truth and White's Holistic Pragmatism: Notes on a Recent Finding Among Rawls's Unpublished Papers and Personal Library. History of Political Thought 35(2): 345-77.

Brandom, R. B. 2010. Between Saying and Doing: Towards an Analytic Pragmatism. Oxford: Oxford University Press.

Ducasse, C. J. 1940a. Philosophy and Natural Science. The Philosophical Review 49(2): 12141.

- 1940b. The Nature and Function of Theory in Ethics. Ethics 51(1): 22-37.

Estlund, D. 1998. The Insularity of the Reasonable: Why Political Liberalism Must Admit the Truth. Ethics 108(2): 252-75.

Feyerabend, P. 1975. Against Method. New York: New Left Books.

Fodor, J.; Lepore, E. 1992. Holism: A Shopper's Guide. Cambridge: Blackwell Publishers.

Galisanka, A. 2012. John Rawls's Early Positivism. Draft p.1-23.

Godfrey-Smith, P. 2014. Quine and Pragmatism. In: G. Harman; E. Lepore (eds.) A Companion to W. V.O. Quine. Oxford: Wiley Blackwell.

Gustafsson, M. 2014. Quine's Conception of Explication - And Why It Isn't Carnap's. In: G. Harman; E. Lepore (eds.) A Companion to W. V. O. Quine. Oxford: Wiley Blackwell.

Hahn, L.E.; Shilpp, P.A. (eds.) 1998. Library of the Living Philosophers: The Philosophy of W. O. Quine. Chicago: Open Court.

Hampshire, S. 1949. Fallacies in Moral Philosophy. Mind 58(232): 466-82.

Hansson, S. O. 2003. Ten Philosophical Problems in Belief Revision. Journal of Logic and Computation 13(1): 37-49.

Haslett, D. W. 1987. What Is Wrong With Reflective Equilibria? The Philosophical Quarterly 37(148): 305-11.

Hylton, P. 2002. Analyticity and Holism in Quine's Thought. The Harvard Review of Philosophy

10: $11-26$.

- 2007. Quine. New York: Routledge.

Kornblith, H. 1994. Naturalizing Epistemology. Cambridge: The M.I.T. Press.

Loar, B. 1986. Mind and Meaning. Cambridge: Cambridge University Press.

Lyons, D. 1975. Nature and Soudness of the Contract and Coherence Arguments. In: N. Daniels (ed.) Reading Rawls. New York: Basic Books.

Mikhail, J. 2011. Rawls' Concept of Reflective Equilibrium and its Original Function in 'A Theory of Justice'. Georgetown Public Law and Legal Theory Research Paper 103(11): 130.

Orenstein, A. 2002. W. V. Quine. Chesham: Acumen.

Principia 19(1): 147-169 (2015). 
Pogge, T. 2007. John Rawls: His Life and Theory of Justice. New York: Oxford University Press. Quine, W. V. O. 1951. Two Dogmas of Empiricism. The Philosophical Review 60(1): 20-43.

- 1960. Word and Object. Cambridge: The M.I.T. Press.

—. 1969. Epistemology Naturalized. In: Ontological Relativity and Other Essays. Washington: Library of Congress.

—. 1975. On Empirically Equivallent Systems of the World. Erkenntnis 9: 313-28. . 1976. The Scope and Language of Science. In: The Ways of Paradox and Other Essays. Cambridge: Harvard University Press.

- 1992. Pursuit of Truth. Cambridge: Harvard University Press.

Rawls, J. 1946. A Brief Inquiry into the Nature and Function of Ethical Theory. The Papers of John Rawls, Harvard University Archives, HUM 48 Box 7, Folder 3, p.1-65.

- 1951. Outline of a Decision Procedure for Ethics. The Philosophical Review 60(2): 177-97.

- 1957. Justice as Fairness. The Journal of Philosophy 54(22): 653-62.

- 1971. A Theory of Justice. Cambridge: Harvard University Press.

- 1985. Justice as Fairness: Political, not Metaphysical. Philosophy and Public Affairs 14(3): 223-51. 1993. Political Liberalism. New York: Columbia University Press.

Raz, J. 1990. Facing Diversity: The Case of Epistemic Abstinence. Philosophy and Public Affairs 19(1): 3-46.

Reidy, D. A. 2014. From Philosophical Theology to Democratic Theory: Early Postcards from an Intellectual Journey. In: J. Mandle; D. Reidy (eds.) A Companion to Rawls. Oxford: Blackwell Companions to Philosophy.

Rueff, J. 1929. From the Physical to the Social Sciences. Baltimore: The John Hopkins University Press.

Sayre-Mccord, G. 1996. Coherentist Epistemology and Moral Theory. In: M. Timmons; W. Sinnot-Armstrong (eds.) Moral Knowledge?. New York: Oxford.

Snare, F. 1975. John Rawls and the Methods of Ethics. Philosophy and Phenomenological Research 36(1): 100-12.

Steiner, E. 1988. Methodology of Theory Building. Sydney: Educology Research Associates.

Talisse, R. B. 2007. A Pragmatist Philosophy of Democracy. London: Routledge

Wacker, J. 1998. A definition of theory: research guidelines for different theory building reseach methods in operations management. Journal of Operations Management 16: 36185.

\section{Notes}

${ }^{1}$ For a detailed discussion of this issue, see Steiner (1988).

Principia 19(1): 147-169 (2015). 
${ }^{2}$ Exceptions that deal with Rawls's figure in a more historical perspective are Galisanka (2012); Bevir \& Galisanka (2012); Reidy (2014); Botti (2014) and Pogge (2007), especially pages 3-27.

3 See Ayer 1936.

${ }^{4}$ Ducasse claims that ethics has the same nature, functions and criteria of validity as any other inquiry and the only essential difference between ethical and, e.g., physical theorizing is one of subject matter. Whether one reads (Ducasse 1940b) and then (Rawls 1946) one can clearly state the great extent to which the latter is influenced by the former.

5 The relationship between Rawls and Logical Positivism is well-presented in (Galisanka, 2012). Rawls's unpublished graduate papers are currently held by the Pusey Library of Harvard University. Here I rely heavily on Rawls's "A Brief Inquiry into the Nature and Function of Moral Theory", loose bound typescript, 1946. I am indebted to Denis Coitinho Silveira for sharing with me this essay. The excerpts from Rawls's "Remarks on Ethics" (1946), "The Origin of Ethical Reflection", "Nature of Ethical Thought", (presumably written between 1948 and 1949) and "Excellence and Shame" (1964) I address here are borrowed from (Bevir \& Galisanka, 2012) and (Botti, 2014). I owe my gratitude to Mark Bevir and Daniele Botti for having sent their papers' manuscripts to me. I also take the chance to thank Gregory Gaboardi for his insightful comments on drafts of this article, Denis Coitinho Silveira for all his patience and guidance through Rawlsian waters and an anonymous referee for valuable argumentative suggestions.

${ }^{6}$ See footnote $\mathrm{n} 2$.

${ }^{7}$ Others helped to change the picture. Karl Popper's The Logic of Scientific Discovery; Thomas Kuhn's The Structure of Scientific Revolutions; Norwood Hanson's Patterns of Discovery and Paul Feyerabend's Against Method, to cite a few, played a great role in showing Logical Positivism's key tenets' untenability. Since this is a big, book-length topic, I leave this discussion pending here.

${ }^{8}$ Of great influence to Rawls were also Wittgenstein's approach to feelings and psychology and Nelson Goodman's account of justification. See Botti (2014) and Bevir \& Galisanka (2012) for the relationship between Rawls's thought and the later Wittgenstein and Mikhail (2011) for a discussion of Nelson Goodman's and Rawls's explanation and application of the reflective equilibrium method.

${ }^{9}$ A positive characterization of what makes science, or any inquiry or theory, objective is extremely hard. Whether we define scientific objectivity as faithfulness to facts, value-freedom or freedom from personal biases, or a combination of all of these, we find in case-studies that science frequently cannot deliver full objectivity in this sense. Nonetheless, to judge a theory as to its worth demands that one first have a clear grasp of what kind of worth is being considered. The main task of criticism is to evaluate theory in accordance to its worth. We shall settle here, for the sake of the argument, with an intuitive notion of objectivity. The worth here considered is pragmatic, to the extent it relies on a notion of fruitfulness and theory-building that is Quinean-based. My thesis is that Rawls's theory of justice satisfies our demands of scientific objectivity and methodology to the extent it is constructed and argued for in accordance to Quine's epistemology.

${ }^{10}$ I borrow this definition from Peter Hylton in his (2002), p.13. For didactic further reading, see Hylton (2007), chapters III, VI and VII; Hahn \& Schilpp (1998), chapters I, II, XV and XXV and Fodor \& Lepore (1992), chapter I.

Principia 19(1): 147-169 (2015). 
${ }^{11}$ Physicalism states that all genuine truths (facts) are determined by physical truths (facts). See Quine (1960) and Quine (1992).

12 The empiricist thesis endorsed by Quine states that that everything we know is known from (or deduced from) experience (or sensory encounter with the physical world). The world affects us only through stimulations of sensory receptors. See Quine (1992).

${ }^{13}$ For further reading, see Hahn \& Schilpp (1998), chapter XIII; Hylton (2007), chapters IX and XII and Orenstein (2002), chapter VIII.

14 See Quine (1975) and Feyerabend (1975).

15 See Quine (1960), chapter I.

${ }^{16}$ See Ernest Geller's article at the London Times Literary Supplement, "The Last Pragmatist: The Philosophy of W. V. O. Quine", 25 July 1975.

17 The extent to which this assertion holds is however debatable. See (Godfrey-Smith, 2014).

${ }^{18}$ For further reading, see Orenstein (2002), chapters II and III, Kornblith (1994) and Brandom (2010).

${ }^{19}$ Rawls himself evoked the analogy between the public character of scientific method and his method of ethical theorizing: "Just as the principles of logic, inference and judgment would not be used were there no persons who could think, infer, and judge, the principles of practical reason are expressed in the thought and judgment of reasonable and rational persons and applied by them in their social and political practice. Those principles do not apply themselves, but are used by us in forming our intentions and actions, and plans and decisions, in our relations with other persons." (Rawls 1993, p.107).

${ }^{20}$ The most important of which are, in Rawls's own view, utilitarianism and intuitionism. See his (1971) and his (1985).

${ }^{21}$ Rawls's considered judgments are thus the "counterpart" of Quine's sensory evidence. They are taken to be intersubjective data against which the chosen (theoretical, moral) principles are to be evaluated.

${ }^{22}$ The veil of ignorance requirement goes as follows: to insure impartiality of judgment, the parties shall be deprived of all knowledge of their personal characteristics and social and historical circumstances. They must all know however of certain fundamental interests they all shared and have, plus general facts about psychology, biology, economics, and other social and natural sciences. See Rawls (1951) and Rawls (1971).

${ }^{23}$ Says Rawls: "The two principles of justice [...] seem to be a reasonable proposal. In fact, I should like to show that these principles are everyone's best reply, so to speak, to the corresponding demands of the others. In this sense, the choice of this conception of justice is the unique solution to the problem set by the original position." (Rawls 1971, p. 119, my italics). Rawls's position in this topic has met serious opposition. See Lyons (1975); Sayre-Mccord (1996); Haslett (1987); Bonevac (2004) and Hansson (2003).

${ }^{24}$ See Aristotle's Nicomachean Ethics, chapter III.

${ }^{25}$ In the one piece of ethics Quine published I was able to find he writes of what he claims to be "the methodological infirmity of ethics as compared with science". See his "On the Nature of Moral Values", Theories and Things (1986), p.63.

${ }^{26} 111 \mathrm{n}, 131 \mathrm{n}, 579 \mathrm{n}$ in his (1971) and 379n in his (1993).

${ }^{27}$ I borrow this description of the process of reflection from (Bonevac, 2004).

28 See Quine (1951).

${ }^{29}$ See Quine (1951).

Principia 19(1): 147-169 (2015). 
${ }^{30}$ Here a clear distinction between transcendental and immanent truth must be kept in mind. Acknowledged fallibilists and pragmatists such as Rawls and Quine reject a transcendent concept of truth which ascribes truth values to theories in accordance to their correspondence or incompatibility with extralinguistic facts: there are no facts of such sort. As knowledge is constrained by our epistemic bias, no straightforward correspondence relation between "facts" and propositions can obtain. One can label 'truth' anything one pleases, however; and Quine and Rawls need no notion of truth richer than one which ascribes truth values to any given theory $\mathrm{T}$ in accordance to T's ability to explain/describe/organize phenomena and predict future outcome; in a flexible and unscrupulously opportunistic handling of the trade-off between accommodating the data, conservatism, simplicity and usefulness.

${ }^{31}$ This is how philosopher of science Hilary Putnam interprets pragmatism. See his "A Reconsideration of Deweyan Democracy", in 'Symposium on the Renaissance of Pragmatism in American Legal Thought', p.1671.

${ }^{32}$ For a careful account of this aspect of Quine's philosophy, see Gustafsson, (2014).

${ }^{33}$ Here lay both (a) the explanatory and (b) the predictive power of Rawls's theory of justice: take $M$ to be the set of competent moral judges of some democratic society $\beta$ and $\alpha$ to be the political problem under scrutiny (e.g. the socially just distribution of goods of some sort $x$ ). Rawls's algorithm for the process of reflection is applied by $M$ over $\alpha$. It follows that (i) if disagreement is reduced, Rawlss theory has been corroborated (in Popper's sense) and if (ii) disagreement is not reduced, by simple modus tollens his theory has been falsified. Such lines must be read with caution, however, as the naive ghost of Received View epistemologies still haunts us: the interplay between theory-construction and evaluation is a more complex dynamics than the results brought forth by simple operations of the laws of deductive logic. If that is the case for the physical sciences, what to say of sciences which deal with much more complex data, such as ethics? Confirmation theory difficulties, however, although of great importance, constitute a topic aside of our research agenda and cannot be pursued here. It suffices for our (and Rawls's!) purposes to show that (a) justice as fairness is a theory in the traditional sense (it has both general laws and empirical content); (b) it is a testable theory. It is capable of making predictions which may or may not hold.

${ }^{34}$ For a detailed account of these difficulties, see Bonevac (2004).

${ }^{35}$ Rawls states that different theories of justice should be assessed following the same criteria for theory-based predictions, construction and evidence assessment Quine offers at his (1960). These extra-empirical values are indicated in section II.3, above.

${ }^{36}$ Logical positivism was a major underpinning in analytic philosophy, having dominated philosophy of science and epistemology thoroughly from the 20s to the 60s. After Quine we became to understand science, philosophy of science and scientific methodology with new eyes entirely. Thus when one reads Rawls's (1946) and Rawls's (1971) one must not conclude Rawls's attitude towards ethics has changed - it is rather analytic philosophers' understanding of science, theory-building criteria and epistemological standards which have changed. The rules of the game were modified; the goal — ethics as science — has remained the same.

37 The relationship between Rawls's theory and pragmatism does not constitute an entirely new topic of discussion, and we could not reasonably ascribe his pragmatic commitments solely to Quine's influence on him. This is a book-length, extremely complex topic. See Botti (2014), especially section 1.1 and Talisse (2007).

Principia 19(1): 147-169 (2015). 
${ }^{38}$ In Rawls's words: "We can check an interpretation of the initial situation [...] by the capacity of its principles to accommodate our firmest convictions and to provide guidance where guidance is needed." (Rawls 1971, p.20).

${ }^{39}$ Post-Kantian moral philosophy is undermined with such misguided approach. For a fine presentation and discussion of difficulties of this sort, see Hampshire (1949).

40 "We should view a theory of justice as a guiding framework designed to focus our moral sensibilities and to put before our intuitive capacities more limited and manageable questions for judgment. The principles of justice identify certain considerations as morally relevant and the priority rules indicate the appropriate precedence when these conflict, while the conception of the original position defines the underlying idea which is to inform our deliberations. If the scheme as a whole seems on reflection to clarify and to order our thoughts, and if it tends to reduce disagreements and to bring divergent convictions more in line, then it has done all that one may reasonably ask." (Rawls 1971, p.53).

${ }^{41}$ Quine was not the first to advocate this thesis. In his (1940a) Ducasse claims that philosophy seeks knowledge in the same sense as the natural sciences and therefore its method must necessarily be likewise scientific, for 'scientific' means nothing more and nothing less than 'knowledge yielding'. Hopefully this new philosophy of research becomes widespread and the imaginary boundaries between science and philosophy which keeps preventing knowledge from growing further and farther, still deeply rooted in specialists' views of research from both areas, disappears.

42 Some have argued against the simplifying devices Rawls makes use in the construction of his principles. It is said that since the original position procedure is idealized and hypothetical we need not consider interfering factors and problems of implementation; however, in practical applications of Rawls's procedures those are real concerns that make overlapping consensus not only impractical, but an impossibility. I am at loss to understand how one expects a theorist to build a moral theory taking into account all possible vicissitudes on prediction and application. Processes of belief change are extremely complex; in order to obtain a moral theory that is at all manageable, substantive simplifications are necessary. This is common-knowledge in formal models of belief revision and game theory. An analogy with science can be here again be helpful. An appeal to ideal objects in physics occurs regularly: mass points, frictionless surfaces, isolated systems. These are valuable (and unreal) simplifications used for the sake of analysis. Similarly, Rawls assumes equilibrium can be reached he cannot foresee socio-economical contingencies nor predict people's intuitive judgments at later stages of reflection. Considerations of this sort imply impractical infinite work. Rawls's theory is a heuristic guiding framework, not a closed formal system. It must be constructed, evaluated and adapted vis-à-vis our pragmatic needs. The presentation of the reflection process cannot be made formally precise due to the nature of the process itself (see footnote n40). We reinterpret the initial situation, set up new constraints, add or drop principles and judgments whenever needed. Politics is a dynamical, always evolving affair and it goes without saying that we must correct/change the arrangement of the variables as many times as necessity requires.

Principia 19(1): 147-169 (2015). 